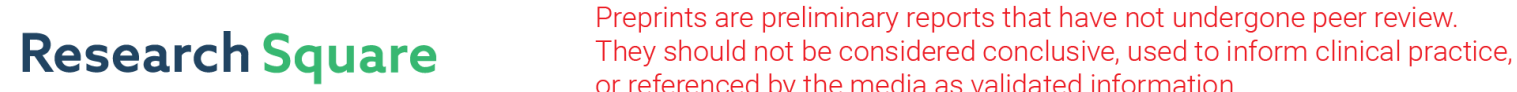 or referenced by the media as validated information. \\ Research on functional boards and plastic films based on animal skin and hydroxyapatite
}

Jiaxing Zhang ( $\nabla$ zjx3199213919@163.com )

Sichuan University - Wangjiang Campus: Sichuan University https://orcid.org/0000-0002-8190-5682

\section{Zhijun Chen}

Xuzhou Hongfeng Circulation Technology Research Institute

Zhongzhen Long

Xuzhou Hongfeng Circulation Technology Research Institute

Zhihua Shan

Sichuan University - Wangjiang Campus: Sichuan University

\section{Research Article}

Keywords: Hydroxyapatite, skin collagen, plasticity compression, protein plastics, transparent

Posted Date: April 26th, 2021

DOI: https://doi.org/10.21203/rs.3.rs-441430/v1

License: (c) (1) This work is licensed under a Creative Commons Attribution 4.0 International License.

Read Full License 


\section{Abstract}

Nano-Hydroxyapatite precursors with calcium and phosphorus salts $(\mathrm{Ca} / \mathrm{P}=1.67)$ were introduced into a three-dimensional collagen network matrix (3DCM) based on goat skin pretreated with glutaraldehyde for in situ growth, and a functional HAG-3DCM board was obtained. After plasticity compression, a transparent protein plastic film was formed. Response surface methodology based on plasticity pressure conditions was used, and the strength, hardness and water resistance of the HAG-3DCM plastic film was significantly improved. This study demonstrates a new approach for the preparation of animal skin materials with new application value.

\section{Introduction}

The use of animal skins has a long history, and even 8000 years ago, animal glue from animal skin extracted by cavepeople in the eastern region was used as a home decoration adhesive. Gelatin from animal skin has played an important role in photography, medical accessories, drug packaging, the food industry and so on. ${ }^{1-3}$ Tanning leather represents the best use of animal skin, and leather products were found in Egyptian pyramids 3,000 years ago. ${ }^{4}$ Animal skin is composed of three parts, namely, the epidermis, dermis and subcutaneous tissue. The main structural component of the dermis is a protein collagen. After the removal of water, interfibrillar substance and fat, collagen accounts for over $95.0 \%$ of the remaining material, most of which is type I collagen, and a small amount is type III collagen. ${ }^{5}$

As a natural renewable resource, protein has become a new research focus as an alternative to petroleum as a flaky material in the field of decorative boards and packaging films. Biobased plastics made of protein or "protein plastics" have the characteristics of low cost, nonbiological toxicity, good degradability. ${ }^{6}$ Protein plastics mainly come from soybean protein, cottonseed protein, corn protein and wheat protein. ${ }^{6-8}$ Because protein generally has inherent defects including poor water resistance, low mechanical properties, poor processability, etc., it is usually used as a filler or additive to blend with ordinary petroleum-based plastic materials, which can reduce the cost of plastic materials and promote plastic decomposition to reduce environmental pollution. ${ }^{9,10}$

Hydroxyapatite $(\mathrm{HA})$ is slightly soluble in water and weakly alkaline $(\mathrm{pH}=7.0 \sim 9.0)$, and it has excellent biological activity, biocompatibility and nontoxicity; it is widely used in bone repair, bone transplantation and drug transportation. ${ }^{11}$ Natural bone is a composite material composed of type I collagen and HA. HA accounts for $70.0 \%$ of the backbone mass and $90.0 \%$ of the remaining $30.0 \%$ organic components are type I collagen. Artificial bone preparation involves adding calcium and phosphate salt solutions to the collagen solution in sequence, and the obtained HA particles are evenly distributed in the collagen matrix or embedded on the surface of the collagen molecule. This type of synthesis method is also called the in situ synthesis law. ${ }^{12}$ A large number of research reports have found that $\mathrm{HA} /$ collagen composites generally have shortcomings such as low mechanical strength, easy swelling, and poor inducing activity, ${ }^{12}$ which limits the application channels. In this paper, HA was introduced into natural three- 
dimensional skin collagen pretreated with glutaraldehyde to induce in situ aggregation, crystal growth and collagen tissue mineralization, ${ }^{13}$ which hardened the collagen matrix and improved the thermal stability; ${ }^{14,15}$ the heat insulation and flame retardant capacities of the composites were measured. Further, the preparation of the protein-based plasticity compression film was studied, ${ }^{16,17}$ and the transparency, water resistance and strength of the film samples were measured. Based on the results, new and potential pathways for functional modification of animal skin are presented.

\section{Experimental}

\subsection{Materials}

Analytically pure diammonium hydrogen phosphate $\left(\left(\mathrm{NH}_{4}\right)_{2} \mathrm{HPO}_{4}\right)$, calcium nitrate $\left(\mathrm{Ca}\left(\mathrm{NO}_{3}\right)\right)$, glycerol, etc., and biological grade hydroxyapatite (HA), were obtained from Chengdu Kelon Chemical Reagent Factory. Industrial grade polyurethane emulsion, was obtained from Xuzhou Hongfeng Polymer Material Company.

Softened goat skin collagen, was obtained from a number of New Zealand salted sheep skins with an area of $0.7 \sim 1.0 \mathrm{~m}^{2}$, and it was prepared and purified by removing the noncollagen components, including the hair, epidermis, grease, and interfibrillar substances. ${ }^{18}$ Finally, the $\mathrm{pH}$ of the skin collagen was adjusted to 4.5 5.0 with $2 \mathrm{~mol} / \mathrm{L}$ ammonium sulfate, and the purified three-dimensional collagen fiber material matrix (3DCM) with a thickness of $0.65 \pm 0.05 \mathrm{~mm}$ was obtained by $10 \mathrm{~kg}$ of centrifugal dehydration.

\subsection{Preparation of micronucleus precursor HA in vitro}

Then, $1000 \mathrm{~mL}$ of deionized water and $200 \mathrm{~g}$ of calcium nitrate and diammonium hydrogen phosphate mixture (according to $\mathrm{Ca} / \mathrm{P}=1.67$ ) were added to the three-necked flask. The $\mathrm{pH}$ value of the solution was adjusted with ammonia to 11.0 , and the solution was stirred at $80^{\circ} \mathrm{C}$ for 12.0 hours and allowed to stand for 12.0 hours. The solution was centrifuged at $10.0 \mathrm{~kg}$, and the precipitate was dried to a constant weight at $105^{\circ} \mathrm{C}$ for sample analysis.

\subsection{Penetration and growth of precursor HA in 3DCM}

3DCM (by dry weight) was weighed and put into a $\$ 600$ drum (Derun Light Industry Machinery Factory, Wuxi, China), and then, $150 \%\left(30^{\circ} \mathrm{C}\right)$ water and $2.0 \%$ glutaraldehyde (by effective content) were added, rotated for $120 \mathrm{~min}$, stopped after $120 \mathrm{~min}$, and rotated again 5 times. Subsequently, the pH was adjusted to $6.0 \sim 6.6$ with $10 \% \mathrm{NaHCO}_{3}$ solution within $60 \mathrm{~min}$, and then, the liquid was drained. Water (150\%) was added, and then, the solution was rotated for $10 \mathrm{~min}$ at $50^{\circ} \mathrm{C}$ to obtain a $0 \#$ sample (3DCM). Based on the $3 \mathrm{DCM}$ sample, $5 \%$ micronucleus precursor $\mathrm{HA}$ and $(1 \sim 4) \times\left(4.0 \% \mathrm{Ca}\left(\mathrm{NO}_{3}\right)_{2}+2.8 \%\left(\left(\mathrm{NH}_{4}\right)_{2} \mathrm{PO}_{4}\right)\right.$ were added according to the $\mathrm{Ca} / \mathrm{P}$ of 1.67 (note $1 \# \sim 4 \#$ ). After rotating at $5 \mathrm{r} / \mathrm{min}$ for 4.0 hours, the solution was allowed to stand for 48.0 hours, and then, it was dried naturally and stretched to obtain, 1\#HAG3DCM 4\#HAG-3DCM samples. 


\subsection{Optimization of the HAG-3DCM sample preparation}

\subsubsection{Determination of the $\mathrm{HA}$ content and $\mathrm{Ca} / \mathrm{P}$ in the samples}

Certain amounts of the 0\#3DCM and 1\#HAG-3DCM 4\# HAG-3DCM samples were dried at $105^{\circ} \mathrm{C}$ to a constant weight. The solution was composed of $V\left(\mathrm{HNO}_{3}\right): V\left(\mathrm{H}_{2} \mathrm{O}_{2}\right)$ at $5.0: 2.0$. It was digested at $100^{\circ} \mathrm{C}$ for 2.0 hours and diluted by a certain multiple. Then the contents of $\mathrm{Ca}$ and $\mathrm{P}$ in the digested samples were measured by ICP (VG PQExCell, TJA Company, USA). The Ca/P ratio and HA content in the samples were calculated.

\subsubsection{Moisture and heat stability test of the samples}

Shrinkage of collagen is a dynamic process. The shrinkage temperature (Ts) reflects the difference in moisture and heat resistance of treated collagen. The Ts values of the 0\#3DCM and 1\#HAG3DCM 4\#HAG-3DCM samples were measured with an SMW-YD1 shrink temperature meter.

According to experiments 2.4.1 and 2.4.2, the optimized HAG-3DCM and its preparation process can be determined.

\subsection{Characteristics of the optimized HAG-3DCM}

\subsubsection{HA structure test of HAG-3DCM}

The optimized HAG-3DCM sample was calcined in a muffle furnace at $800^{\circ} \mathrm{C}$ for $2.0 \mathrm{~h}$ to remove organic components, and then the calcination residual was washed with water to remove soluble inorganic components. After drying, an X-ray diffractometer (X'PertProMPDY129, Nalytical, Netherlands) was used for the remaining inorganic phases. The construction of outsourced biograde HA and HA in the optimized HAG-3DCM was analyzed and compared. The selected scanning angle step was $0.02^{\circ}$, the scanning range was $10.0 \sim 70.0^{\circ}$, and the scanning speed was $2^{\circ} / \mathrm{min}$.

\subsubsection{Morphology of precursor HA and HA in HAG-3DCM}

To observe the morphology of precursor HA and HA in the optimized HAG-3DCM, the precursor HA and the optimized HAG-3DCM samples were calcined in a muffle furnace at $800^{\circ} \mathrm{C}$ for $2.0 \mathrm{~h}$, and then, two calcined residuals were washed with water to remove the organic and soluble inorganic components. After drying, TEM analysis was performed on two calcined residuals that were fixed on the sample platform with conductive adhesive, and the surface morphology was observed by a Tecnai G2F20 microscope (S-Twin, FEl Corporation, USA).

\subsubsection{Element distribution characteristics in EDS}

To understand the penetration and accumulation growth of HA precursors in 3DCM, EDS scanning was performed on the 3DCM cross-section at selected points based on the phosphorus-rich region and 
scanning was carried out at a diameter of $0.005 \mathrm{~mm}$ by energy dispersive X-ray spectroscopy (EDS, JSM7500F, Japan Electronics Co., Japan).

\subsubsection{Morphology of HAG-3DCM}

The morphology of collagen fiber bundles in the optimized HAG-3DCM was observed by scanning electron microscopy (JSM-7500F, JEOL Corporation, Japan). The test surface was sprayed with gold, and the acceleration voltage was $3.00 \mathrm{kV}$.

\subsection{Functional characterization of HAG-3DCM plate materials}

\subsubsection{HAG-3DCM thermal insulation test}

The thermal conductivity of the optimized HAG-3DCM was characterized by the steady-state method to measure the thermal conductivity of the sample. Using the coefficient of the thermal conductivity tester (DRP- $\mathbb{Z}$, Xiangtan Xiangjiang Instrument Co., Ltd.). First, the sample was placed between the upper and lower copper plates and heated to the set temperature. When the temperature of the upper and lower copper plates was stable, the temperatures $T_{1}$ and $T_{2}$ were recorded. Next, the sample was removed, the copper plate was heated to $T_{3}$ (higher than $T_{2}$ ), heating was stopped, and then, the change in temperature of the lower copper plate over time was recorded again.

$$
\lambda=-m c \frac{2 h_{p}+R_{p}}{2 h_{p}+2 R_{p}} \times \frac{1}{\pi R^{2}} \times \frac{h}{T_{1}-T_{2}} \times\left.\frac{d T}{d t}\right|_{T=T_{2}}
$$

where $m$ is the mass of the lower copper plate, $\mathrm{g} ; \mathrm{c}$ is the specific heat capacity of the copper plate, $\mathrm{kJ} /(\mathrm{K} \cdot \mathrm{kg}) ; h_{p}$ and $R_{p}$ are the thickness and radius of the lower copper plate, respectively, $\mathrm{mm} ; h$ is the sample thickness, $\mathrm{mm}$; and $\mathrm{T}_{1}$ and $\mathrm{T}_{2}$ are the temperatures of the upper and lower copper plate, respectively, ${ }^{\circ} \mathrm{C}$. The basic diagram is shown in Figure 1.

\subsubsection{Flame retardant test of HAG-3DCM}

The optimized HAG-3DCM was tested according to GB/T2406-1993 (Plastics Combustion Performance Test-Oxygen Index Method). An oxygen index tester (JF-3, Nanjing Jionglai Company) was used to test the limiting oxygen index of the samples. The combustion time was $15.0 \mathrm{~s}$ and the combustion length was $5.0 \mathrm{~cm}$.

\subsubsection{Test of the physical and mechanical characteristics of HAG-3DCM}

Tested samples of the optimized HAG-3DCM were cut and kept at constant temperature $\left(25.0^{\circ} \mathrm{C}\right)$ and humidity $(65.0 \% \mathrm{RH})$ for $24 \mathrm{~h}$. According to the standard QB/T2710-2005 the tensile strength and elongation at break of the samples were measured by using a universal tension machine (AL7000SN, Taiwan High-speed Railway Technology Company). At $25^{\circ} \mathrm{C}$, the rising rate of the instrument was 50 $\mathrm{mm} / \mathrm{min}$. Each group of samples was measured in 5 parallel tests, and the average value was taken. 


\subsection{Functional characterization of HAG-3DCM plastic films}

\subsubsection{Preparation of plasticity pressed films}

3DCM and optimized HAG-3DCM samples were cut into small pieces of $10 \times 20 \mathrm{~cm}$ and uniformly coated with $100 \mathrm{~g} / \mathrm{m}^{2}$ glycerin on both sides. The samples were dried completely in a vacuum at $35.0^{\circ} \mathrm{C}$, and then kept at constant temperature $\left(25.0^{\circ} \mathrm{C}\right)$ and constant humidity $(65.0 \% \mathrm{RH})$ for $24.0 \mathrm{~h}$. The samples were placed in the die of a hot press, which was designed according to the response surface test. The molding temperature was set at 100,130 and $160^{\circ} \mathrm{C}$, the pressure was set at $8.0,10.0$ and $12.0 \mathrm{MPa}$, and the molding time was set at 5,10 and $15 \mathrm{~min}$. The plasticity pressed samples were referred to as 3DCM protein plastic (3DCM-PP) and HAG-3DCM protein plastic (HAG-3DCM-PP).

\subsubsection{Hardness test of the 3DCM-PP and HAG-3DCM-PP}

According to the GB 2411-1980 method, the 3DCM-PP and HAG-3DCM-PP samples were cut with a sampler. A shore hardness tester (LX-A-1, Wenzhou Weidu Electronics Co., Ltd.) was used to apply $1.0 \mathrm{~kg}$ of load and pressure for $30.0 \mathrm{~s}$, and the Shore hardness value of each sample was recorded.

\subsubsection{Strength test of the 3DCM-PP and HAG-3DCM-PP}

According to the GB/T1040-92 plastic tensile property test method, the 3DCM-PP and HAG-3DCM-PP samples were cut with a sampler. The tensile strength and elongation at break of the samples were measured by universal tensile machine (AL-7000SN, High-speed Rail Technology Co., Ltd.), and the tensile rising rate was $50.0 \mathrm{~mm} / \mathrm{min}$. Each group was measured in parallel 3 times, and the average values of the tensile strength and elongation at break of each sample were recorded.

\subsubsection{Swelling property test of the 3DCM-PP and HAG-3DCM-PP}

3DCM-PP and HAG-3DCM samples of the same amount were placed into Petri dishes and immersed in $50.0 \mathrm{~mL}$ of deionized water for $24.0 \mathrm{~h}$ at $37.0^{\circ} \mathrm{C}$, then, the surface moisture was removed with filter paper, and the samples were weighed. Three sets of parallel values were measured, and the average value was calculated as the swelling degree of the sample. The sample swelling degree is calculated by equation (2):

$$
S=\frac{M \mathrm{~s}-M}{M} \times 100 \%
$$

where $S$ is the swelling degree (\%), $M$ is the initial mass $(\mathrm{g})$, and $M_{S}$ is the swelling mass $(\mathrm{g})$.

\subsubsection{Light transmittance test of the 3DCM-PP and HAG-3DCM-PP}

The 3DCM-PP and HAG-3DCM samples were cut to a size of $2.0 \times 5.0 \mathrm{~cm}$. The transmittance of the samples in three different locations was measured by a light transmittance tester (LS116, Shenzhen 
Lianhuicheng Technology Co., Ltd.) in the length direction, and the average values were obtained.

\subsubsection{Flexural resistance of the 3DCM-PP and HAG-3DCM-PP}

According to the standard of leather torsion fastness (QB/T 2714-2018), constant temperature $\left(25.0^{\circ} \mathrm{C}\right)$ and constant humidity $(65.0 \% \mathrm{RH})$ conditions were applied for $24.0 \mathrm{~h}$, and then, the 3DCM-PP or HAG3DCM-PP films were placed in a torsion fastness tester (XK-3014, Jiangsu Xiangke Instrument Company, China). The film size was $70 \times 45 \mathrm{~mm}$ and the winding angle was $22.5^{\circ}$. The maximum torsion fastness was observed by 5 cycles until cracks were observed under $5 \times$ magnification.

\section{Results And Discussion}

\subsection{Optimized HAG-3DCM}

The analysis results of the complex formed by HA growth in the 3DCM sample are shown in Table 1. Ca and $P$ determined by ICP after digestion of HAG-3DCM and $w(\mathrm{HA}) / \%$ were calculated according to a Ca/P of 1.67. The results show that $0 \# 3 D C M$ contains negligible amounts of HA and 1\# 4\#HAG-3DCM are close to the $\mathrm{Ca}_{10}\left(\mathrm{PO}_{4}\right)_{6}(\mathrm{OH})_{2}$ structure in 3DCM. The Ca/P ratios in 1\# 4\#HAG-3DCM are all higher than 1.67 because there was a small amount of $\mathrm{Ca}$ in $3 \mathrm{DCM}$, which was derived from the preparation process of 3DCM. Table 1 shows that the addition of $\mathrm{Ca}\left(\mathrm{NO}_{3}\right)_{2}$ and $\left(\mathrm{NH}_{4}\right)_{2} \mathrm{PO}_{4}$ in $4 \# \mathrm{HAG}-3 \mathrm{DCM}$ compared with $3 \# H A G-3 D C M$ increases by $25 \%$, although the effective binding $w(\mathrm{HA}) / \%$ increases by $0.08 \%$. The Ts values of $1 \# \sim 4 \#$ HAG-3DCM are mainly from glutaraldehyde tanning; thus, the difference among them is small, but the $3 \#$ is much closer to the $4 \#$ Ts. Therefore, $3 \#$ HAG-3DCM can be considered to have reached the stabilization effects, turning point and represents the optimized process for the preparation of 3DCM in this experiment. Hereafter, this variant is called HAG-3DCM in the experimental samples.

\section{Table 1 Analysis of HA in HAG-3DCM}

\begin{tabular}{|llll|}
\hline EXPNO & $\mathrm{Ca} / \mathrm{P}$ & $w(\mathrm{HA}) / \%$ & $\mathrm{Ts} /{ }^{\circ} \mathrm{C}$ \\
$0 \#$ & - & 0.02 & 57.8 \\
$1 \#$ & 1.68 & 3.90 & 78.1 \\
$2 \#$ & 1.72 & 6.08 & 78.7 \\
$3 \#$ & 1.73 & 7.96 & 79.4 \\
$4 \#$ & 1.73 & 8.04 & 79.5 \\
\hline
\end{tabular}

\subsection{Element distribution characteristics in HAG-3DCM}

Since almost no $\mathrm{P}$ is observed in $3 \mathrm{DCM}$, it represents the aggregation point of $\mathrm{HA}$ in the phosphorus-rich region. Four HA growth points were identified by scanning from the 3DCM surface in an approximate range of $0.7 \mathrm{~mm}$. The elemental analysis is shown in Figure 2. According to the analysis of the surface 
scanning results, the $\mathrm{Ca} / \mathrm{P}$ in HA-3DCM was 1.71 1.80, which was larger than that of standard HA. When the $\mathrm{pH}$ is higher than the $\mathrm{pl}$ of $3 \mathrm{DCM}$, the penetration and combination of $\mathrm{Ca}^{2+}$ in $3 \mathrm{DCM}$ is easier while that of $\mathrm{PO}^{3-}$ is impeded; thus, $\mathrm{Ca} / \mathrm{P}$ can not meeting the theoretical value of 1.67 .

\subsection{Morphology of the HA precursor and HA in HAG-3DCM}

\subsubsection{HA morphology in 3DCM}

The two calcination residuals from the precursor HA and HA in the HAG-3DCM sample were observed by TEM, as shown in Figure 3. Compared with the HA from the precursor, the HA from HAG-3DCM was similar to the precursor HA in a columnar shape, although the diameter of the precursor HA was less than $100 \mathrm{~nm}$, and HA particles in the HA-3DCM sample were more bonded and slightly larger in volume. Therefore, crystal growth occurs in the 3DCM sample, as shown in Figure 3.

\subsubsection{HA structure in HAG-3DCM}

The XRD spectra of standard HA ${ }^{19}$ and inorganic phase samples in the HAG-3DCM sample were compared, as shown in Figure 4. The main diffraction peaks of the inorganic phase in the body correspond to the characteristic diffraction peaks of the standard HA in Figure 4, in which the characteristic peaks (002), (210), (211), (300) and (213) appear in turn. It was further confirmed that the inorganic phase in the HA-3DCM sample was HA.

\subsubsection{Formation process of HAG-3DCM}

According to the preparation process of HAG-3DCM and the morphology and structure of HA, the crystal growth process of HA in $3 D C M$ is shown in Figure 5.

\subsection{Structure and function of HAG-3DCM}

\subsubsection{HAG-3DCM fiber bundle braiding}

By comparing the SEM images of the cross-section and longitudinal section of raw material 3DCM and compound HAG-3DCM. As shown in Figure 6, the formation of HA in the 3DCM caused the HAG-3DCM fiber bundles to separate from the aggregates, which is consistent with the mechanism of the separation and fixation of skin collagen tissues by tanning agents in the tanning chemistry. Thus, HAG-3DCM can be considered a new type of chrome-free tanned leather.

\subsubsection{Heat insulation of HAG-3DCM}

The thermal conductivity of 3DCM and the HAG-3DCM film was measured by the steady state method at $60^{\circ} \mathrm{C}$, as shown in Table 2. The thermal conductivity of HAG-3DCM is decreased from $0.25 \mathrm{~W} / \mathrm{K} \cdot \mathrm{m}$ to 0.12 $\mathrm{W} / \mathrm{K} \cdot \mathrm{m}$ compared with that of $3 \mathrm{DCM}$. The decrease in thermal conductivity is caused by cavitation (see Figure 5) of the collagen matrix after 3DCM is treated with HA, and the increase in porosity leads to a decrease in thermal conductivity. ${ }^{20}$ 
Table 2 Thermal conductivity of HAG-3DCM

\begin{tabular}{|lll|}
\hline Samples & 3DCM & HAG-3DCM \\
\hline$\lambda \otimes \mathrm{W} / \mathrm{K} \cdot \mathrm{m} \square$ & 0.25 & 0.12 \\
\hline $\mathrm{LOI} / \%$ & 20.6 & 26.5 \\
\hline
\end{tabular}

\subsubsection{HAG-3DCM flame retardancy}

In the combustion process, a carbonization layer is formed on the surface of the 3DCM and HAG-3DCM samples. The many internal pores in HAG-3DCM can store the generated ammonia nitrogen and block the oxygen and external heat sources to prevent further combustion. ${ }^{21}$ Table 2 shows that HAG-3DCM has a relatively high limiting oxygen index of $26.5 \%$.

\subsubsection{Physical and mechanical characteristics of HAG-3DCM}

Table 3 shows the physical and mechanical values of the HAG-3DCM. Due to the lack of a standard comparison, the sample was used as a type of leather for reference in this experiment. Compared with the national standard of chrome-free upper leather $(\leq 1.0 \mathrm{~mm})$, it can be seen that except for the bursting force, the other indexes such as the tensile strength, tearing strength, and load elongation all meet the requirements.

Table 3 Physical and mechanical properties of chrome-free leather $(\leq 1.0 \mathrm{~mm})$

\begin{tabular}{|lllll|}
\hline Samples and Standards & bursting & tearing & tensile & elongation \\
& $/(\mathrm{N} / \mathrm{mm})$ & $/(\mathrm{N} / \mathrm{mm})$ & $/ \mathrm{MPa}$ & $(10 \mathrm{~kg}) / \%$ \\
\hline HAG-3DCM & 359 & 28.1 & 10.0 & 73.2 \\
\hline QB/T 1873-2010 $(\leq 1.0 \mathrm{~mm})$ & $\geq 400$ & $\geq 21$ & $\geq 8.0$ & $\leq 35$ \\
\hline
\end{tabular}

\subsection{Plasticity pressing and HAG-3DCM film}

\subsubsection{Optimization of plasticity pressing}

The 3DCM and HAG-3DCM samples were plastically pressed to prepare the 3DCM-PP and HA-3DCM-PP protein plastic films. Taking the tensile strength of the plastic film as the performance index of the sample tested, the influence of different molding pressures, molding times and molding temperatures on the tensile strength of the protein plastic film sample was evaluated.

Tensile strength is related not only to the strength of a single fiber, but also to the number of fibers per unit cross section. The greater the strength of a single fiber and the greater the number of fibers per unit cross section, the greater the tensile strength. For a protein-based structure, as the density increases, the binding between molecules and molecular chains is strengthened until reaching a limit. 
A response surface analysis was performed on the tensile strength test results of the sample with a thickness of $1.0 \pm 0.12 \mathrm{~mm}$, as shown in Figure 7. When the molding time was $11.0 \mathrm{~min}$, the tensile strength of the protein plastics increased with increasing pressure. When the molding time was 11.0 min, the increase in temperature had little effect on the tensile strength of the sample.

According to the results shown in Figure 7, Table 4 integrates the analysis of pressure, temperature and time factors and obtains the order of influence as follows: pressure $>$ temperature $\approx$ time.

\section{Table 4 Effect of the factors on the sample tensile strength}

\begin{tabular}{|lll|}
\hline Test factor & F(HAG-3DCM-PP) & $F(3 \mathrm{DCM}-\mathrm{PP})$ \\
\hline A-pressure & 63.8 & 64.9 \\
\hline B-temperature & 9.26 & 20.5 \\
C-time & 11.7 & 12.4 \\
\hline
\end{tabular}

For 3DCM, in addition to the pressure factor, the influence of the time factor is greater than that of the temperature because when the temperature is higher than $100^{\circ} \mathrm{C}$, the $3 \mathrm{DCM}$ is subjected to thermal denaturation and gelation, which easily results in a rapid increase in the density of the 3DCM-PP and a change in the tensile strength because the rheological velocity becomes a major factor.

For the HAG-3DCM-PP, the temperature factor is greater than the time factor. Although the entry and growth of HA greatly improves the gelling resistance and inhibits the rheological rate after gelation of HAG-3DCM, the gelling degree of the HAG-3DCM-PP is greatly affected when the temperature is over $100^{\circ} \mathrm{C}$.

The optimal test conditions for the 3DCM-PP and HAG-3DCM-PP and the tensile strength of the samples are analyzed according to the response surface, as shown in Table 5. The tensile strength of the HAG3DCM-PP is better than that of the 3DCM-PP and exceeds 41.0 MPa. This indicates that HA aggregates and grows in 3DCM, which can mineralize collagen fibers well, stabilize the structure of 3DCM, and significantly increase the tensile strength of the plastic film. For the two kinds of films, the optimum conditions that have common significance are a pressure of $10.5 \mathrm{MPa}$, temperature $135^{\circ} \mathrm{C}$ and time of $11.0 \mathrm{~min}$.

Table 5 Optimum conditions and sample tensile strength 


\begin{tabular}{|lll|}
\hline Test factor & 3DCM-PP & HAG-3DCM-PP \\
\hline Pressure/MPa & 10.5 & 10.7 \\
\hline Temperature $/{ }^{\circ} \mathrm{C}$ & 135.0 & 136.0 \\
\hline Time/min & 11.8 & 11.4 \\
\hline Tensile strength/MPa & 26.0 & 67.0 \\
\hline
\end{tabular}

\subsubsection{HAG-3DCM plastic film function}

The 3DCM-PP film and HAG-3DCM-PP film were prepared under optimized plastic pressure conditions (pressure10.5 $\mathrm{MPa}$, temperature $135^{\circ} \mathrm{C}$ and time11.0 min). The tensile strength, elongation at break, flexural resistance, hardness, swelling rate and light transmittance of the sample were tested, and the results are shown in Table 6.

\section{Table 6 Physical performance of the two protein plastic films}

\begin{tabular}{|llc|}
\hline Indicators & 3DCM-PP & HAG-3DCM-PP \\
\hline Tensile strength/MPa & 26.0 & 67.0 \\
\hline Elongation at break/\% & 18.0 & 11.0 \\
\hline Flexural resistance/times & $0 \sim 5$ & $45 \sim 50$ \\
\hline Shaw hardness & 95.0 & 96.0 \\
\hline Swelling rate/\% & 55.0 & 12.0 \\
\hline Light transmittance/\% & 71.0 & 55.0 \\
\hline
\end{tabular}

After HA enters 3DCM to form HAG-3DCM, a special stabilization effect or mineralization effect occurs, under which tensile strength and hardness are increased and the water swelling resistance is greatly improved. Although the transparency of 3DCM is higher than that of HAG-3DCM (as shown in Figure 8), the pores between the fibers in HAG-3DCM can be removed by plasticity pressure to satisfactorily improve its transparency. According to the comparison of the flexural resistance in Table 6, without HA support, glycerol could not improve the tortuous resistance of 3DCM. The data shown in Table 6 show that 3DCM has potential application value.

\section{Conclusions}

When nano-HA precursors with calcium and phosphorus salts $(\mathrm{Ca} / \mathrm{P}=1.67)$ were infiltrated into the threedimensional collagen network matrix (3DCM) based on goat skin pretreated with glutaraldehyde for insitu growth, an ecological animal skin function board called HAG-3DCM was obtained. The collagen tissue was fixed or mineralized in the form of dispersion or cavitation. After plasticity compression a 
transparent protein plastic film (HAG-3DCM-PP) was formed. For the optimization of plasticity pressure conditions, the strength, hardness and water resistance of HAG-3DCM were significantly improved compared with the 3DCM (without HA). This study demonstrates a new approach to the preparation of ecological materials from animal skins with new application value.

\section{References}

[1] Lee CJ, Chang YC, Wang LW, Wang YH (2018) Nonvolatile resistive switching memory utilizing cobalt embedded in gelatin. Materials 11: 32 .

[2] Cetinkaya T, Altay F, Ceylan Z (2021) A new application with characterized oil-in-water-in-oil double emulsions: Gelatin-xanthan gum complexes for the edible oil industry. LWT-Food Sci Technol 138: 110773.

[3] Hussain A, Hasan A, Babadaei MMN, Bloukh SH, Edis Z, Rasti B, Sharifi M, Falahati M (2020) Application of gelatin nanoconjugates as potential internal stimuli-responsive platforms for cancer drug delivery. J Mol Liq 318: 114053.

[4] Luo W, Si Y, Wang H, Qin Y, Huang FC, Wang CS (2011) Leather material found on a 6th B.C. Chinese bronze sword: A technical study. Acta A Mol Biomol Spectrosc 79: 1630-1633.

[5] Menon GK (2002) New insights into skin structure: scratching the surface. Adv Drug Deliver Rev 54: S3-S17.

[6] Scheller J, Conrad U (2005) Plant-based material, protein and biodegradable plastic. Curr Opin Plant biol 8: 188-196.

[7] Samarasinghe S, Easteal AJ, Edmonds NR (2008) Biodegradable plastic composites from corn gluten meal. Polymer International. Polym Int 57: 359-364.

[8] Jagadeesh D, Kumar BP, Sudhakara P, Prasad CV, Rajulu AV, Song JI (2013) Preparation and properties of propylene glycol plasticized wheat protein isolate novel green films. J Polym Environ 21: 930-936.

[9] Tkaczyk AH, Otaigbe JU, Ho KG (2001) Bioabsorbable soy protein plastic composites: effect of polyphosphate fillers on biodegradability. J Polym Environ 9: 19-23.

[10] Chen WJ, Ding J, Yan XM, Yang W, He M, Yin GQ (2019) Plasticization of cottonseed protein/polyvinyl alcohol blend films. Polymers 11: 2096.

[11] Pinheiro ALB, Gerbi MEM, Limeira FA, Ponzi EAC, Marques AMC, Carvalho CM, Santos RC, Oliveira PC, Nóia M, Ramalho LMP (2009) Bone repair following bone grafting hydroxyapatite guided bone regeneration and infra-red laser photobiomodulation: a histological study in a rodent model. Laser Med Sci 24: 234-240. 
[12] Chang MC, Ikoma T, Kikuchi M, Tanaka J (2001) Preparation of a porous hydroxyapatite/collagen nanocomposite using glutaraldehyde as a crosslinkage agent. J Mater Sci Lett 20: 1199-1201.

[13] Koutsopoulos S (2002) Synthesis and characterization of hydroxyapatite crystals: a review study on the analytical methods. J Biomed Mater Res 62: 600-612.

[14] Chang MC, Ko C, Douglas WH (2003) Preparation of hydroxyapatite-gelatin nanocomposite. Biomaterials 24: 2853-2862.

[15] Kikuchi M, Ikoma T, Itoh S, Matsumoto HN, Koyama Y, Takakuda K, Shinomiya K, Tanaka J (2004) Biomimetic synthesis of bone-like nanocomposites using the self-organization mechanism of hydroxyapatite and collagen. Compos Sci Technol 64: 819-825.

[16] Paetau I, Chen CZ, Jane J (1994) Biodegradable plastic made from soybean products. II. Effects of cross-linking and cellulose incorporation on mechanical properties and water absorption. J Environ Polym Degrad 2: 211-217.

[17] Otaigbe JU, Adams DO (1997) Bioabsorbable soy protein plastic composites: Effect of polyphosphate fillers on water absor ption and mechanical properties. J Environ Polym Degrad 5: 199208.

[18] Thanikaivelan P, Rao JR, Nair BU, Ramasami T (2004) Progress and recent trends in biotechnological methods for leather processing. TRENDS Biotechnol 22: 181-188.

[19] Rahavi SS, Ghaderi O, Monshi A, Fathi MH (2017) A comparative study on physicochemical properties of hydroxyapatite powders derived from natural and synthetic sources. Russ $\mathrm{J}$ Non-Ferr Met 58: 276-286.

[20] Sciamanna V, Nait-Ali B, Gonon M (2015) Mechanical properties and thermal conductivity of porous alumina ceramics obtained from particle stabilized foams. Ceram Int 41: 2599-2606.

[21] Guo WW, Liu JJ, Zhang P, Song L, Wang X, Hu Y (2018) Multi-functional hydroxyapatite/polyvinyl alcohol composite aerogels with self-cleaning, superior fire resistance and low thermal conductivity. Compos Sci Technol 158: 128-136.

\section{Figures}




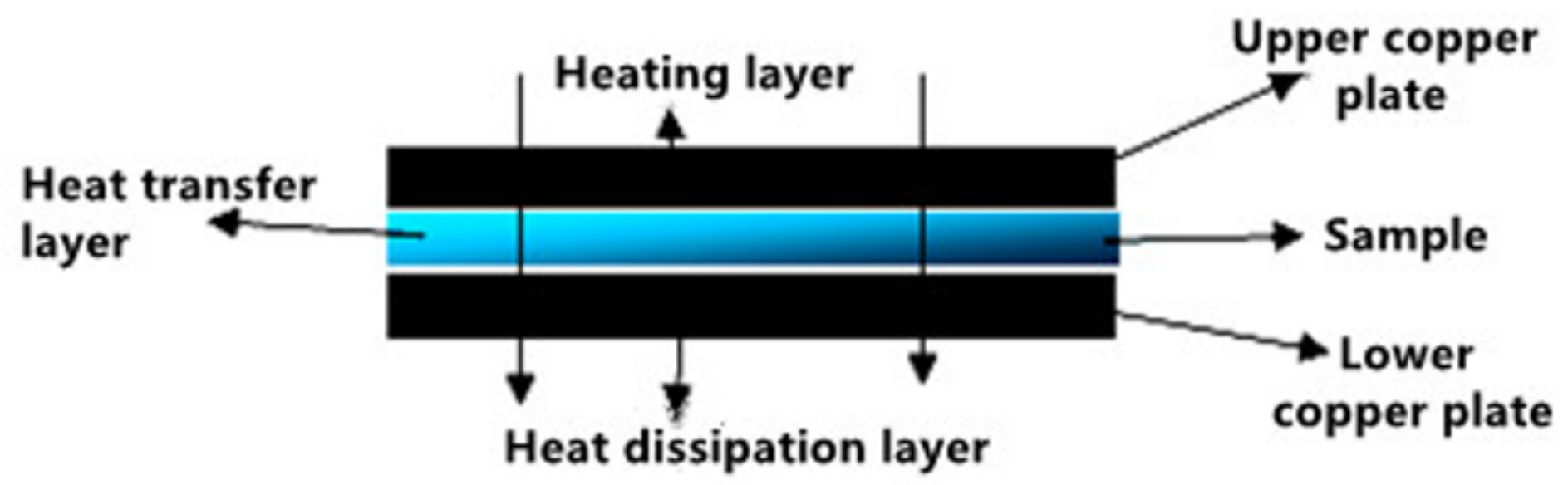

Figure 1

Principle of the heat conduction test

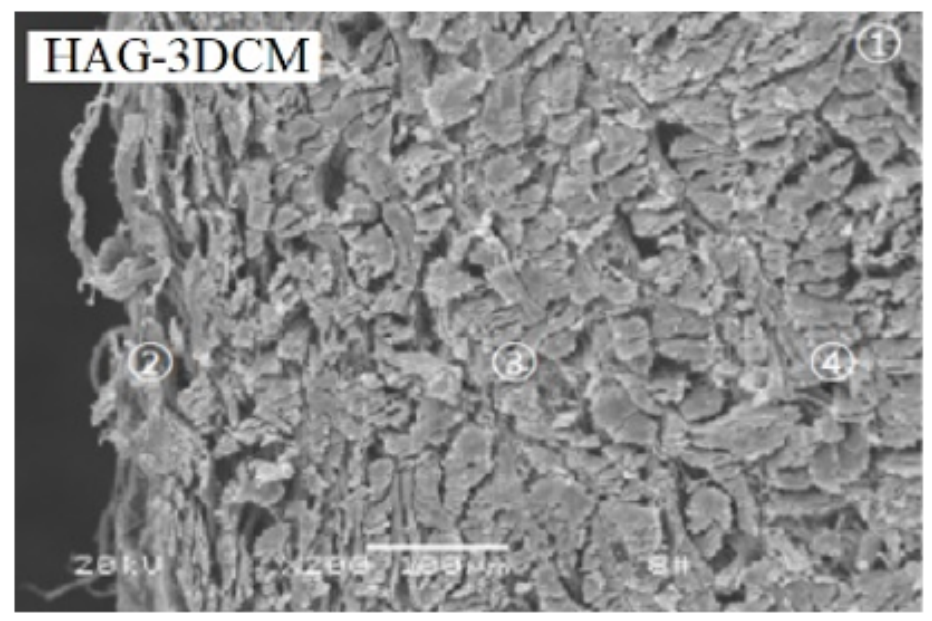

\begin{tabular}{ccccc}
\hline & \multicolumn{3}{l}{ weight\% in four points } \\
\cline { 2 - 5 } & 1 & 2 & 3 & 4 \\
\hline $\mathrm{C}$ & 48.7 & 41.7 & 43.4 & 47.7 \\
$N$ & 21.3 & 14.4 & 18.2 & 20.1 \\
$O$ & 26.1 & 22.7 & 30.5 & 29.3 \\
$\mathrm{Ca}$ & 2.20 & 14.9 & 5.60 & 1.60 \\
$P$ & 1.00 & 6.50 & 2.40 & 0.70 \\
$\mathrm{Cl}$ & 0.40 & 0.60 & 0.40 & 0.40 \\
$\mathrm{Na}$ & 0.30 & 0.20 & 0.50 & 0.20 \\
\hline
\end{tabular}

Figure 2 
Elemental ratio of HA growth point
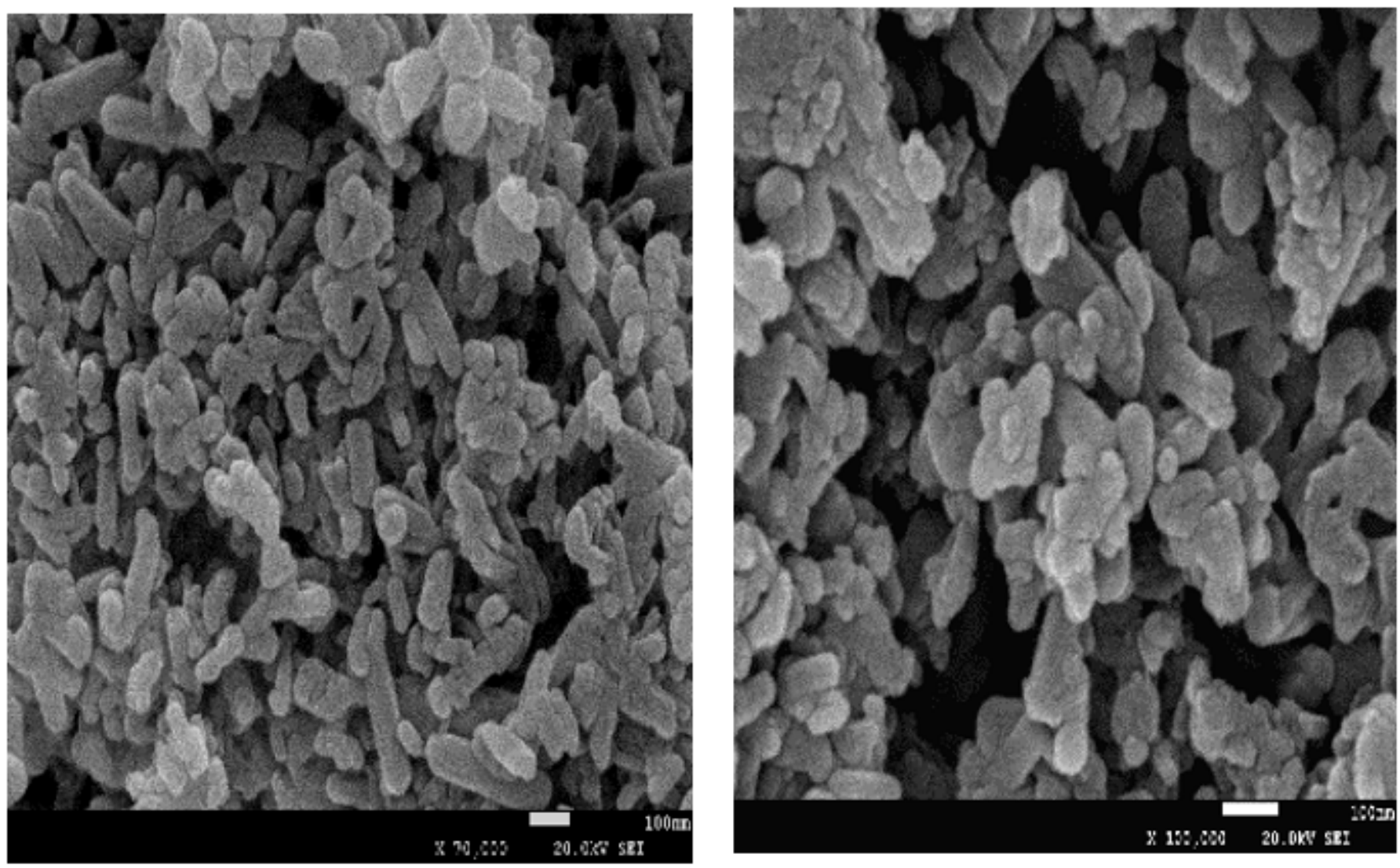

Figure 3

TEM morphology of the precursor HA (left) and in vivo HA (right)

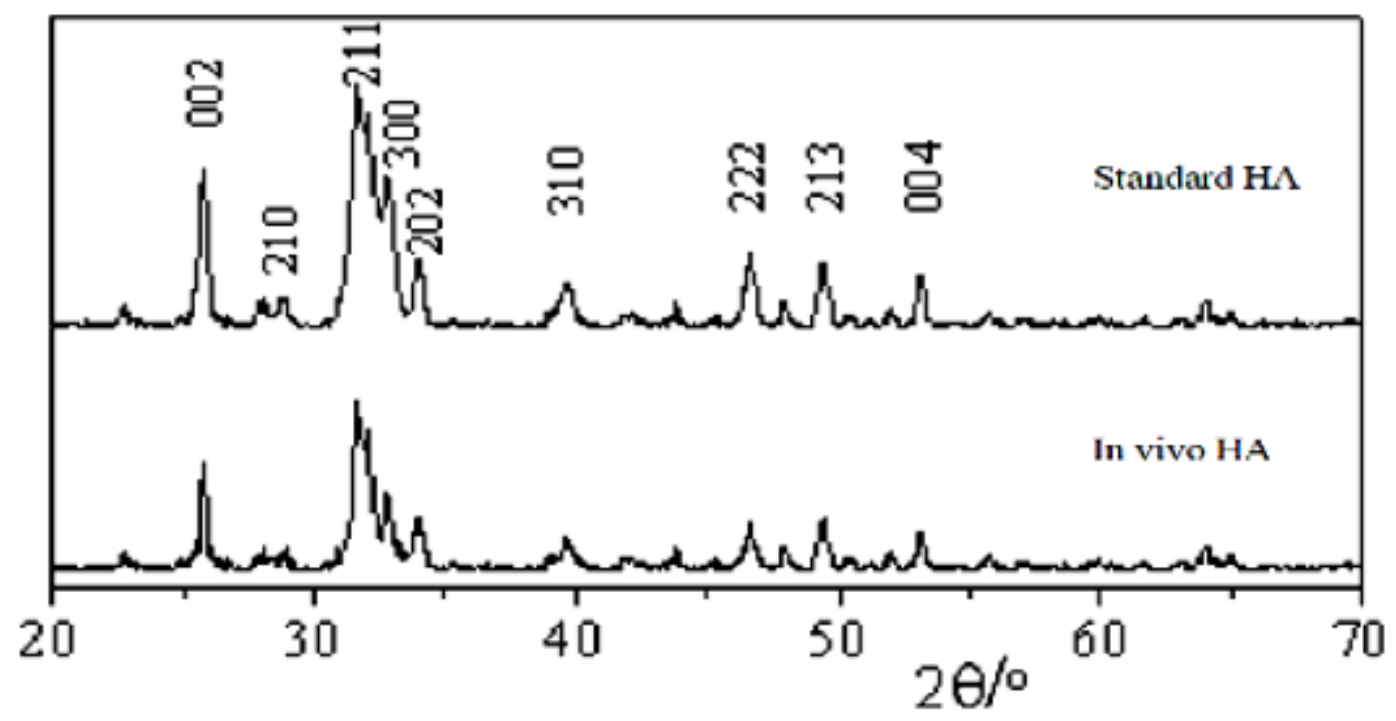

Figure 4

XRD of standard $\mathrm{HA}$ and in vivo $\mathrm{HA}$ 


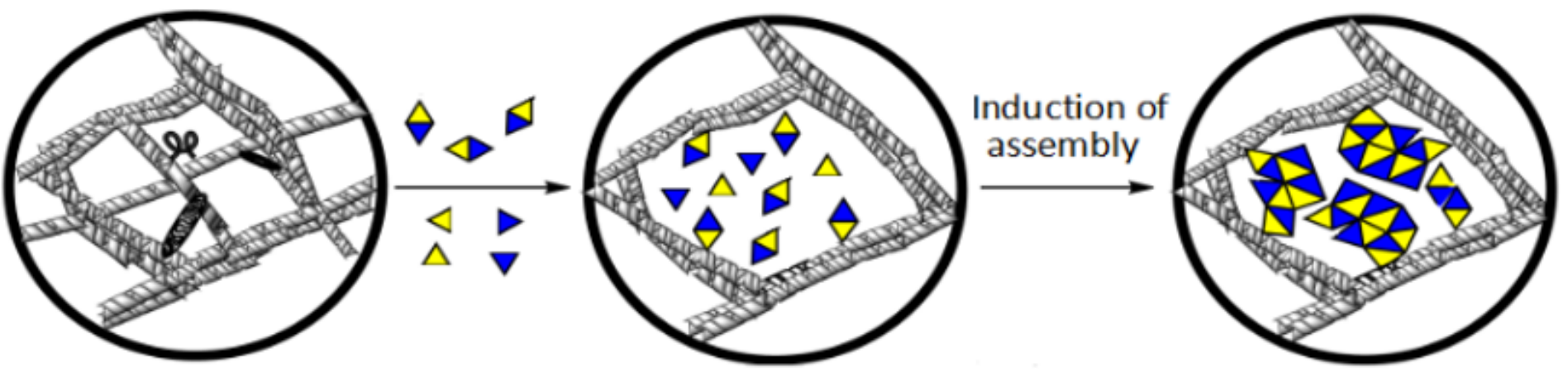

Figure 5

In vivo growth process of HA
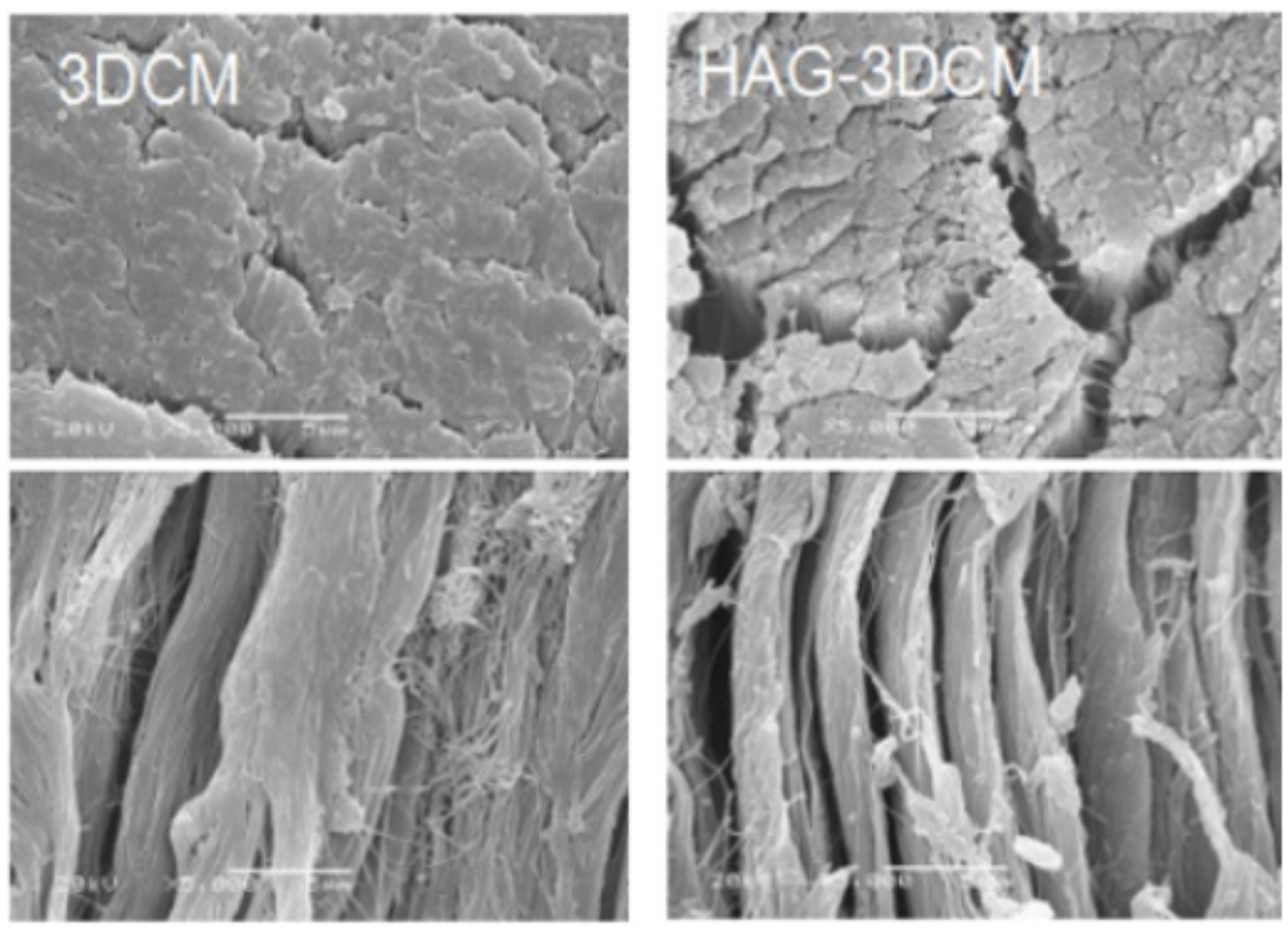

Figure 6

SEM image of the collagen matrix before and after HA treatment 

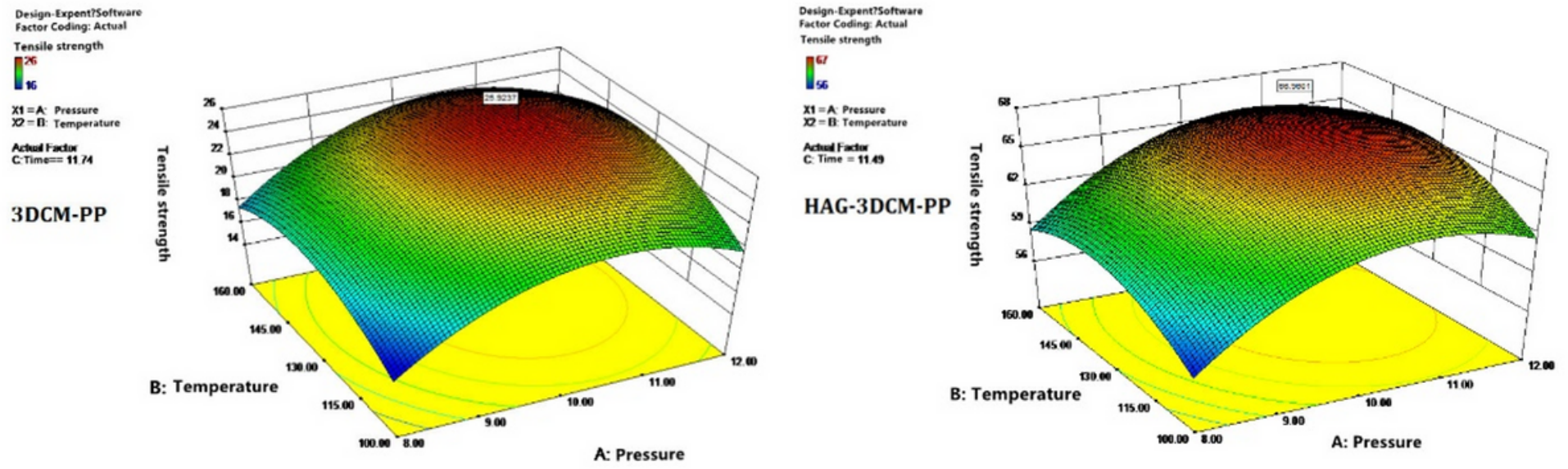

Figure 7

3D diagram of response surface analysis of plasticity compression for 3DCM-PP
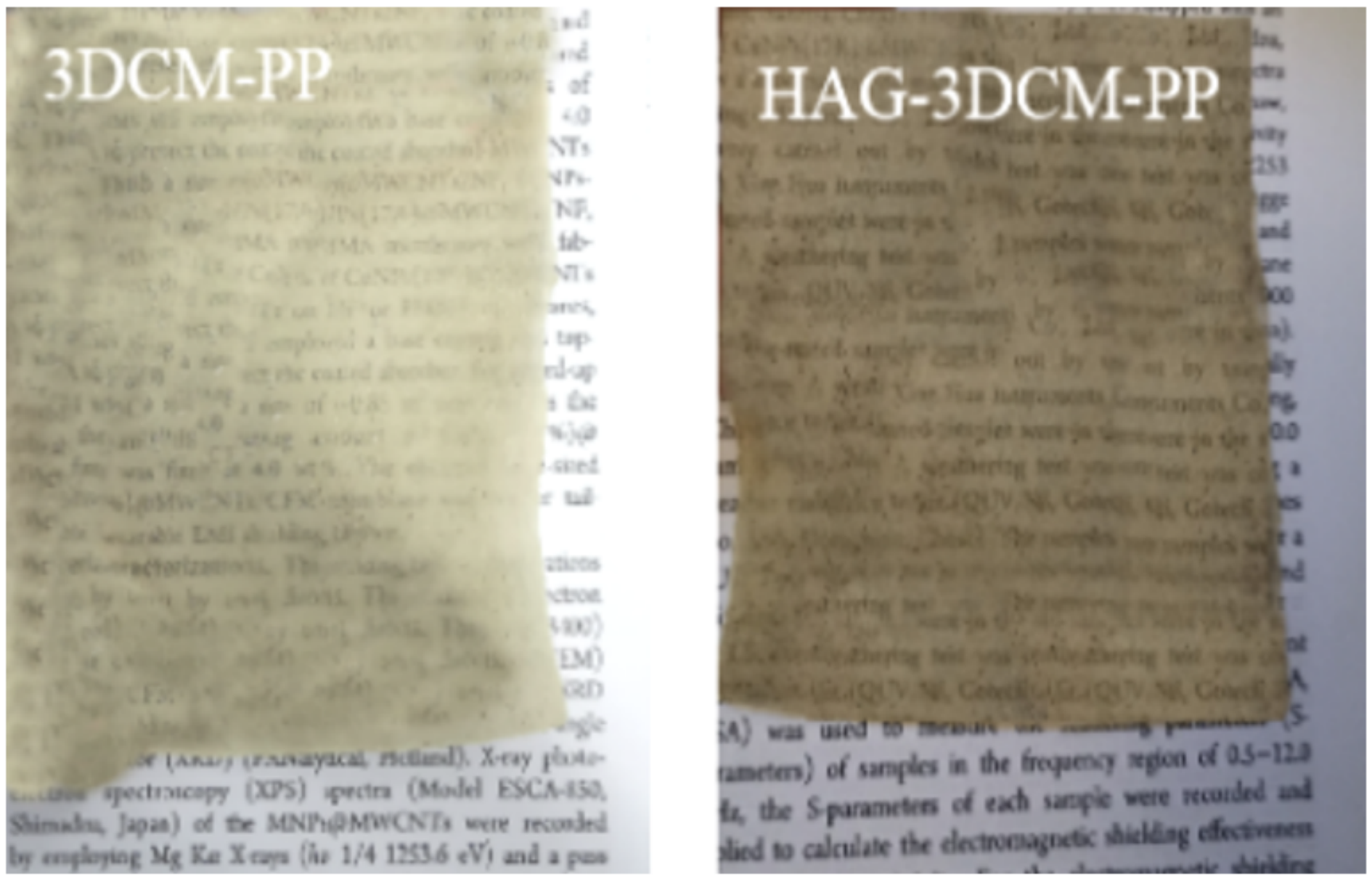

\section{Figure 8}

Appearance of two kinds of protein plastic films

\section{Supplementary Files}


This is a list of supplementary files associated with this preprint. Click to download.

- GraphicalAbstract.docx 